\title{
LOAD RESPONSE AND GAP FORMATION IN A SINGLE-ROW \\ CRUCIATE SUTURE ROTATOR CUFF REPAIR
}

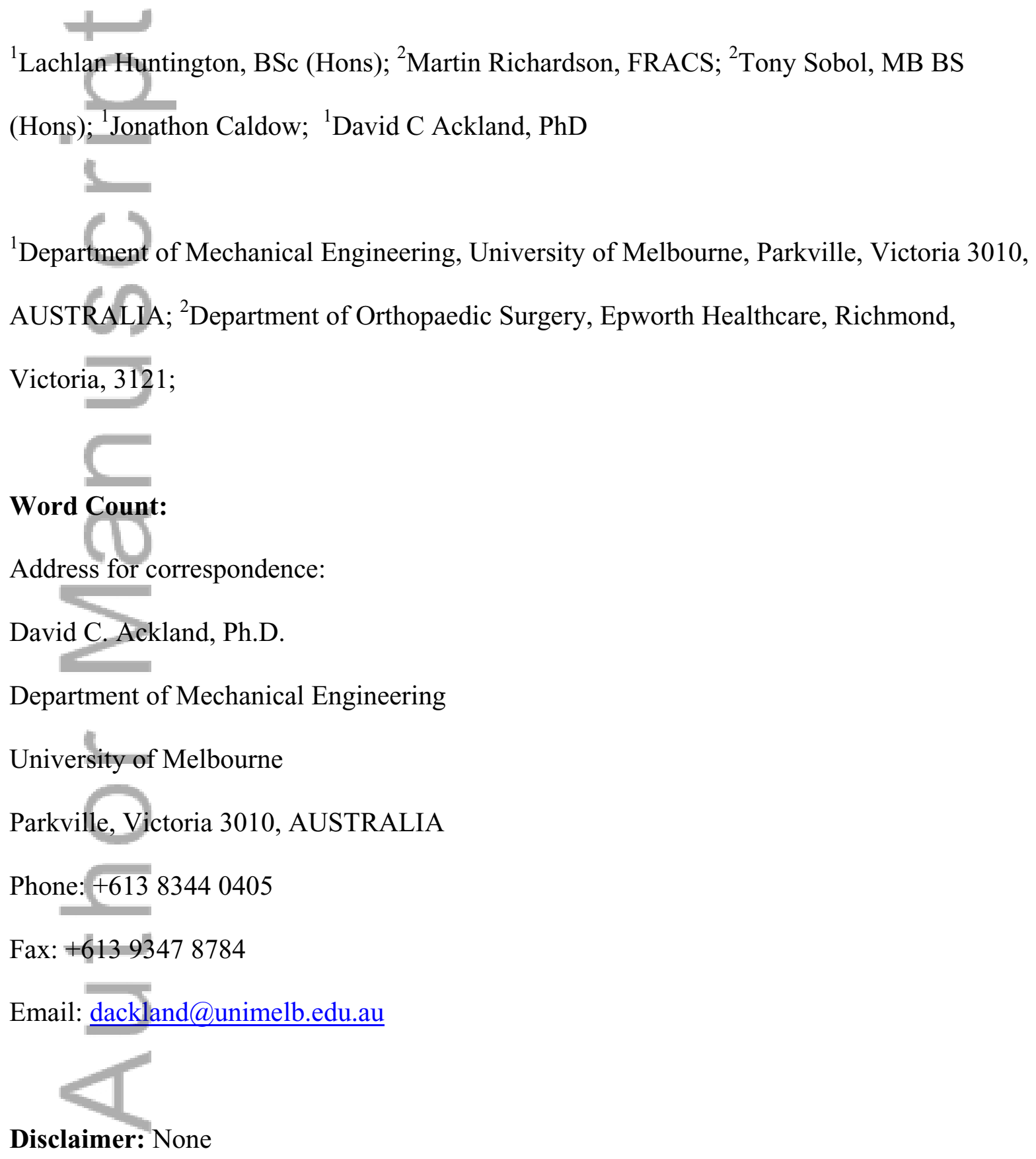

${ }^{1}$ Lachlan Huntington, BSc (Hons); ${ }^{2}$ Martin Richardson, FRACS; ${ }^{2}$ Tony Sobol, MB BS

(Hons); ${ }^{1}$ Jonathon Caldow; ${ }^{1}$ David C Ackland, PhD

${ }^{1}$ Department of Mechanical Engineering, University of Melbourne, Parkville, Victoria 3010, AUSTRALIA; ${ }^{2}$ Department of Orthopaedic Surgery, Epworth Healthcare, Richmond, Victoria, 3121;

\section{Word Count:}

Address for correspondence:

David C. Ackland, Ph.D.

Department of Mechanical Engineering

University of Melbourne

Parkville, Victoria 3010, AUSTRALIA

Phone: +613 83440405

Fax: +61393478784

Email: dackland@,unimelb.edu.au

\section{Disclaimer: None}

This is the author manuscript accepted for publication and has undergone full peer review but has not been through the copyediting, typesetting, pagination and proofreading process, which may lead to differences between this version and the Version of Record. Please cite this article as doi: 10.1111/ans.13875

This article is protected by copyright. All rights reserved. 
Keywords: shoulder, tendon, fatigue, reconstruction, stiffness, surgery

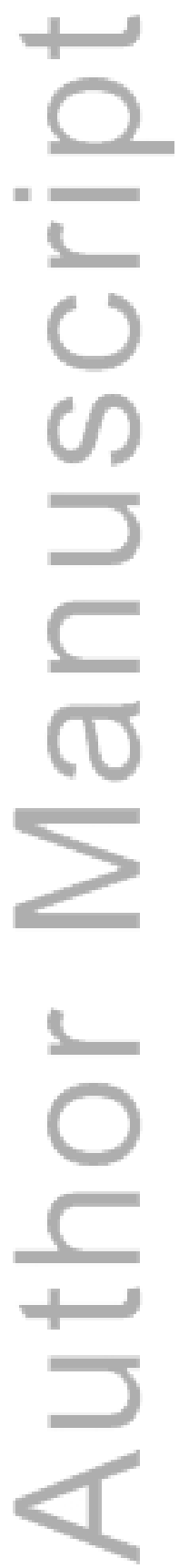

This article is protected by copyright. All rights reserved. 


\begin{abstract}
Background: Double-row rotator cuff tendon repair techniques may provide superior contact area and strength compared to single row repairs, but are associated with higher material expenses and prolonged operating time. The purpose of this study was to evaluate gap formation, ultimate tensile strength and stiffness of a single-row cruciate suture rotator cuff repair technique, and to compare these results to those of the Mason-Allen and SutureBridge repairs.

Methods: Infraspinatus tendons from twenty-four spring lamb shoulders were harvested and allocated to cruciate suture, Mason-Allen and SutureBridge repair groups. Specimens were loaded cyclically between 10 and $62 \mathrm{~N}$ for 200 cycles, and gap formation simultaneously measured using a high-speed digital camera. Specimens were then loaded in uniaxial tension to failure, and construct stiffness and repair strength evaluated.
\end{abstract}

Results: Gap formation in the cruciate suture repair was significantly lower than that of the Mason-Allen repair (mean difference $=0.6 \mathrm{~mm}, \mathrm{p}=0.009$ ) and no different to that of the SutureBridge repair $(\mathrm{p}>0.05)$. Both the cruciate suture repair (mean difference $=15.7 \mathrm{~N} / \mathrm{mm}$, $\mathrm{p}=0.002$ ), and SutureBridge repair (mean difference $=15.8 \mathrm{~N} / \mathrm{mm}, \mathrm{p}=0.034$ ) were significantly stiffer than that of the Mason-Allen repair; however, no significant differences in ultimate tensile strength between repair groups were discerned $(p>0.05)$.

Conclusion: The cruciate suture repair construct, which may represent a simple and costeffective alternative to double-row and double-row equivalent rotator cuff repairs, has comparable biomechanical strength and integrity to that of the SutureBridge repair, and may 
result in improved construct longevity and tendon healing compared to the Mason-Allen repair. Word Count: 250

\section{INTRODUCTION}

Surgical repair of full-thickness rotator cuff tear aims to re-establish the fibrovascular interface between the tendon and bone, which is necessary for healing and restoration of the fibrocartilagenous tendon insertion. High biomechanical fixation, as well as reproduction of the native tendon anatomical footprint, has been shown to lead to improved construct performance under loading ${ }^{4}$ however, recurrent tearing of the repaired has been reported in 20 to $82 \%$ of cases. ${ }^{8,11}$ Causes of rotator cuff repair failure include anchor pull-out, surgical knot loosening, and suture breakage or tendon tear at another location; however, suture pullout through the tendon has been shown to be the most common construct failure mode in both single- and double-row repairs, and occurs at a load that depends greatly on the given tendon repair technique.$^{3}$

The ultimate tensile strength and stiffness of a repair construct are frequently used as a surrogate measure of the construct integrity. Since the mean time between primary and revision tendon repair has been shown to be 7.7 weeks, which represents approximately $51-64 \%$ of the time required for total tendon healing, ${ }^{21}$ the immediate and short-term biomechanical strength of a repair may be clinically relevant in healing and construct longevity. ${ }^{7}$ The single-row MasonAllen repair has been shown to exhibit greater ultimate tensile strength compared with simple single row repairs, ${ }^{3}$ but exhibits a lower ultimate tensile strength than that of double row and double-row equivalent repairs.${ }^{15,20}$ Double-row techniques provide superior tensile strength compared to single row repairs due to the increased number of anchors, tendon-suture 
perforations and the overall greater tendon footprint available for tendon-suture integration; ${ }^{16}$ however, a number of studies have found no difference in the stiffness between the double-row, Mason-Allen, and double-row equivalent SutureBridge repairs immediately after repair. ${ }^{20}$ These $^{2}$ somewhat counterintuitive results suggest the presence residual suture slack in the repair construct prior to loading. Cyclical loading or pre-conditioning of the repaired tendon immediately after surgery has been shown to increase the construct's measured stiffness. ${ }^{14}$ Gap formation under cyclic loading has been used as a measure of repair integrity and longevity, since motion at the tendon-bone interface can delay or inhibit tendon-bone healing. It has been shown in a rat model that prolonged repetitive loading at the repaired tendon complex has been associated with significantly increased collagen fiber organization, decreased matrix metalloproteinase expression and less fibrocartilage 21 days postoperatively. ${ }^{12}$ The Mason-Allen repair has been shown to exhibit larger gap formation compared with the traditional double row repair ${ }^{19}$ and the SutureBridge repair, ${ }^{22}$ whilst other studies have shown the SutureBridge and double row repairs to exhibit equivalent gap formation. Since double row repairs are associated with higher material expenses, prolonged operating time, and are technically more difficult for the surgeon, greater emphasis has been placed on improving the functional performance and clinical outcome of single-row procedures.

- Caldow et al (2015) reported a single-row cruciate suture repair consisting of two bone anchors with four suture perforations through the tendon from each anchor, which are tied off in mattress stitches at $45^{\circ}$ to each other. It was shown that the cruciate suture repair exhibited similar footprint contact area and pressure to that of the double row repair. ${ }^{6}$ Despite 
these apparent advantages, gap formation has not been evaluated in this construct, and its long-term strength integrity remains largely unknown. The objective of this study was to develop a biomechanical model to evaluate the fixation strength of the cruciate suture repair. The specific aims were twofold. Firstly, to quantify gap formation, ultimate tensile strength and stiffness of the cruciate suture repair, and secondly, to compare these results to those of the single-row Mason-Allen repair and the double-row equivalent SutureBridge repair.

\section{MATERIALS AND METHODS}

Specimen preparation

Twenty-four fresh-frozen spring lamb shoulders of six-month age were obtained and all soft tissue from the proximal humerus and scapula of each specimen were removed by sharp dissection. The infraspinatus tendon was detached from the infraspinatus fossa of the scapula and greater tuberosity of the humerus, and its muscle resected. Anatomical measurements of all specimens were performed with digital callipers (Absolute Digital Caliper 500 Series, Mitutoyo, USA) including infraspinatus tendon thickness at origin and insertion, tendon width at insertion and origin, tendon length, humeral thickness at nutrient artery level, humeral head width and humerus length. All specimens were screened for macroscopic signs of degeneration. Specimens were stored at $-20{ }^{\circ} \mathrm{C}$ following dissection and were thawed for 24 hours prior to experimentation.

\section{Surgical repair technique}

Specimens were randomly assigned to three repair groups: (1) single-row cruciate suture repair consisting of two overlapping stitches oriented $45^{\circ}$ to the tendon (Fig. 1A), ${ }^{6}$ (2) single-row 
Mason-Allen repair consisting of a mattress stitch and overlapping simple stitch (Fig. 1B) and (3) double-row equivalent knotless SutureBridge repair consisting of two medial row mattress stitches with the free suture limbs passing to two lateral row anchors (Fig. 1C). All surgeries were performed with non-absorbable suture anchors (Smith \& Nephew Inc, London, UK) and No. 2 Fiberwire suture. In the case of the SutureBridge repair, knotless absorbable SwiveLock ${ }^{\circledR}$ anchors were used in the lateral row (Arthrex, Naples, Florida, USA). The initial knot tied for each stitch was a sliding half-hitch knot, followed by four half-hitch knots in alternating posts. All surgeries were performed by two qualified orthopaedic surgeons at one practice using a standardised technique.

\section{Experimental protocol}

All repair constructs underwent cyclic loading followed immediately by load-tofailure testing using an Instron materials testing system (Instron, Model 3521, Parker Hydraulics) instrumented with a 10kN uni-axial load cell (Instron 67918, Instron, UK) sampling at $50 \mathrm{~Hz}$. The medial end of the tendon was fixed in a customised sinusoidal grip clamp, which was attached to the load cell and upper crosshead of the Instron system (Fig. 2A). The proximal humerus was embedded in a cylindrical potting block with Plaster of Paris. An adjustable alignment bracket was used to orient the humerus to ensure that tension applied to the infraspinatus tendon was in the direction of the muscle line of action.

A $10 \mathrm{~N}$ pre-tension was initially applied to the repaired tendon for approximately 10 seconds to remove residual tendon slack and backlash in the fixtures. The tendon was then loaded to $62 \mathrm{~N}$, which represents the approximate force generated in the supraspinatus during elevation of the upper limb to 90 degrees. ${ }^{1}$ The tendon was then unloaded to $10 \mathrm{~N}$, and this load cycle repeated at a frequency of $0.25 \mathrm{~Hz}$ for 200 cycles, simulating the initial conditioning 
loading of the construct post-operatively. ${ }^{13,14}$ The position of pairs of fiducial markers placed on the greater tuberosity of the humerus, $10 \mathrm{~mm}$ lateral to the tendon edge, and superficial lateral tendon, $5 \mathrm{~mm}$ medial to the edge of the repair, was recorded with a high definition digital video camera (Canon EOS 7D, Tokyo, Japan) at a sampling frequency of $50 \mathrm{~Hz}$. During testing, specimens were kept moist by irrigation with saline solution.

Tendon displacement was quantified from the change in position of the two tendon markers relative to the two humeral markers using digital image analysis (Fig. 2B and 2C). ${ }^{15}$ Gap formation at a given load cycle was defined as the peak-to-peak difference in tendon displacement relative to bone between that load cycle and the initial load cycle ${ }^{15}$. Gap formation was calculated as the average tendon marker displacement measured from the two adjacent tendon-bone markers. Following cyclic loading, each repaired tendon was then loaded in tension to failure by displacing the tendon at a constant rate of $1 \mathrm{~mm} / \mathrm{s}^{6}$ whilst simultaneously sampling applied force and displacement at $50 \mathrm{~Hz}$. Ultimate tensile strength was defined as the maximum tensile load that occurred just prior to complete disruption of the repair construct. ${ }^{6,15}$ Repair construct stiffness was calculated from the gradient of the line of best fit applied to the resultant load-displacement curve. ${ }^{6,19}$

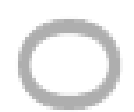

Statistical analysis

A Kruskal-Wallis single-way analysis of variance (ANOVA) for non-parametric data was used to analyse differences in gap formation, ultimate tensile strength and stiffness of the three repair groups. Tukey HSP post hoc testing was used to evaluate mean differences between groups and calculate $95 \%$ confidence intervals. Based on an expected gap formation of $2.5 \mathrm{~mm}$, $1.7 \mathrm{~mm}$ and $1.7 \mathrm{~mm}$ in the Mason-Allen, SutureBridge and cruciate suture repairs groups, 
respectively, ${ }^{14,16,19}$ a sample size of $\mathrm{n}=24$ ( $\mathrm{n}=8$ in each group) was determined. ${ }^{4}$ This equates to an effect size of 0.754 , and a study power of 0.817 . Standard deviation and standard error of the mean were calculated and used as a measure of the dispersion of the measured data. Significance level was set at $\mathrm{p}<0.05$. Statistical analysis were performed using the statistical package for Social Science (PASW Statistics 18, SPSS Inc., IL)

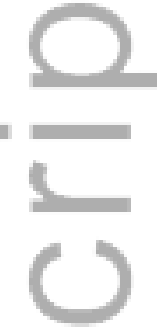

\section{RESULTS}

Ultimate tensile strength and stiffness

No statistically significant differences in ultimate tensile strength were observed between the cruciate suture, Mason-Allen and SutureBridge repairs $(p<0.05)$; however, the cruciate suture repair exhibited a larger ultimate tensile strength $(240.7 \pm 23.1 \mathrm{~N})$ compared to that of the Mason-Allen $(172.0 \pm 15.3 \mathrm{~N})$ and SutureBridge repair $(184.1 \pm 15.7 \mathrm{~N})$. The cruciate suture repair exhibited significantly greater stiffness compared to that of the MasonAllen repair $($ mean difference $=15.7 \mathrm{~N} / \mathrm{mm}, 95 \%$ CI $[1.3,30.1], \mathrm{p}=0.020)($ Table 1$)$. The SutureBridge also exhibited significantly greater stiffness compared to that of the MasonAllen repair (mean difference $=15.8 \mathrm{~N} / \mathrm{mm}, 95 \%$ CI $[1.4,30.2], \mathrm{p}=0.034)$. No significant differences in stiffness were observed between the cruciate suture repair and SutureBridge repair $(\mathrm{p}<0.05)$, which were $61.6 \pm 4.6 \mathrm{~N} / \mathrm{mm}$ and $61.7 \pm 4.4 \mathrm{~N} / \mathrm{mm}$, respectively. Mean Pearson coefficient of regression values, $\mathrm{R}^{2}$, for stiffness regression calculations were notsignificantly different between groups.

\section{Gap Formation}

This article is protected by copyright. All rights reserved. 
The Mason-Allen repair exhibited significantly greater gap formation compared with that of the SutureBridge repair and cruciate suture repair after 50, 100, 150 and 200 load cycles $(\mathrm{p}<0.01)$ (see Table 1$)$. After 50 cycles of loading, the gap formation in the MasonAllen repair was $0.6 \mathrm{~mm}$ larger than that of the SutureBridge repair $(95 \%$ CI $[0.2,1.0], \mathrm{p}=$ $0.002)$ and $0.5 \mathrm{~mm}$ larger than that of the cruciate suture repair $(95 \% \mathrm{CI}[0.1,0.9], \mathrm{p}=0.001)$ (Supplementary Material). After 200 cycles, the gap formation in the Mason-Allen repair was $0.6 \mathrm{~mm}$ larger than that of the SutureBridge repair $(95 \%$ CI $[0.2,1.1], \mathrm{p}=0.002)$ and $0.6 \mathrm{~mm}$ larger than that of the cruciate suture repair $(95 \% \mathrm{CI}[0.2,1.0], \mathrm{p}=0.009)$. The cruciate suture repair demonstrated a slightly greater mean gap formation compared with that of the SutureBridge, however, this trend was non-significant $(\mathrm{p}>0.05)$.

\section{DISCUSSION}

The present study found gap formation in the SutureBridge $(1.1 \pm 0.1 \mathrm{~mm})$ and cruciate suture repairs $(1.1 \pm 0.1 \mathrm{~mm})$ to be significantly less than that of the Mason-Allen repair $(1.7 \pm$ $0.2 \mathrm{~mm})$ at 200 load cycles. The difference in gap formation between these repairs is in reasonable agreement with previous studies. ${ }^{2,22}$ For example, Wellman et al (2009), using a bovine subscapularis tendon model, reported $41 \%$ smaller gap formation in a SutureBridge repair compared with that of the Mason-Allen repair ${ }^{22}$ - a finding similar to that reported in the present study (37\%). Furthermore, a bovine infraspinatus model reported gap formation in the SutureBridge construct to be significantly less than that of the Mason-Allen repair at 1, 200 and 500 cycles. ${ }^{2}$ The finding that the cruciate suture repair exhibits less gap formation than that of the Mason-Allen repair may be due to the differing suture configurations. The increased number of tendon perforations and the crossed nature of the cruciate sutures orients suture passes at $45^{\circ}$ to 
the tendon line of action, which been shown to increase tendon-bone contact area and pressure compared with that of the Mason-Allen repair. ${ }^{6}$ This suture configuration may increase the frictional force between tendon and bone through increased contact pressure, and contribute to reduced dynamic tendon slippage under tractional forces. Ultimately, this may result in lower gap formation compared to that in constructs where suture passes are oriented parallel to the tendon collagen fibre direction, or in cases where suture passes create low contact pressure. Previous studies have suggested that high gap formation is linked to impaired biological tendon-bone healing ${ }^{18}$ and increased re-tear rates following rotator cuff tendon repair $^{9}$. Therefore, a repaired tendon should exhibit sufficient fixation strength to prevent gap formation and re-tear through pull-out. The results of the present study show that the cruciate suture repair exhibits similar gap formation, stiffness and ultimate tensile strength to the double-row equivalent SutureBridge repair, and improved strength and gap formation relative to the Mason-Allen repair. The biomechanical performance demonstrated in the present study, in conjunction with the contact area and pressure outcomes reported in a previous study, ${ }^{6}$ suggest that the cruciate suture and SutureBridge repairs may result in similar shortterm clinical performance. The SutureBridge may be more time consuming and costly than the cruciate suture repair, as four anchors must be placed, as is the case with other doublerow constructs. ${ }^{5,15}$ While the faster 'SpeedBridge' repair may provide speed advantages over the SutureBridge repair, since it is knotless, the cruciate suture repair involves placement of only a single row of bone anchors, and thus, may represent a quicker, easier and more cost effective alternative to double-row and some double-row equivalent repair techniques. In the present study, the stiffness of the cruciate suture $(61.6 \pm 4.6 \mathrm{~N} / \mathrm{mm})$ and SutureBridge repairs $(61.7 \pm 4.4 \mathrm{~N} / \mathrm{mm})$ were significantly greater than that of the Mason-Allen 
repair $(45.8 \pm 4.4 \mathrm{~N} / \mathrm{mm})$. These reported stiffness values, however, are notably larger than those reported in other studies. ${ }^{6,19}$ For example, Caldow et al (2015) reported a cruciate suture repair construct stiffness of $10.9 \pm 4.1 \mathrm{~N} / \mathrm{mm}$, which is $18 \%$ of the value reported in the present study. ${ }^{6}$ This observation was also reported in a study by Kim et al (2006), which compared stiffness in double-row and single-rows repairs after a cyclic loading regiment. ${ }^{14}$ Kim et al (2006) showed there was a $100.3 \%$ and $191.4 \%$ increase in linear stiffness between the first and $200^{\text {th }}$ cycles, respectively. The greater repair construct stiffness reported in the present study may be a consequence of suture movement during the cyclic loading that was applied prior to the final tendon pull out and stiffness measurement. Tendon cyclic pre-loading is likely to eliminate residual slack in the sutures resulting in an overall less compliant repair construct and a more stable suture fixation within the collagen network of the tendon; however, this would only occur if the tendon-bone motion threshold for healing is not exceeded, which in a previous study has been identified as a gap formation of greater than $4 \mathrm{~mm} .{ }^{17}$ The results suggest that early passive mobilisation of the upper limb to preload the construct may improve its stiffness and stability characteristics, and in the absence of excessive muscle and joint loading, contribute to improved healing.

There are a number of limitations of the present study. First, the young ovine infraspinatus tendon used in the present study may not be representative of human rotator cuff tendon anatomy, and do not model the degenerative tendon state observed clinically in many patients that present for reconstruction. However, the ovine infraspinatus is a frequently used model of the human supraspinatus due to macroscopic similarities in tendon morphology and histology, ${ }^{10}$ and provides a sound model for evaluating relative differences between surgical repair groups. As such, no significant between-group differences were found in tendon or 
humeral anatomy (Supplementary Material). Second, the present study examined the immediate and short-term biomechanical behaviour of rotator cuff repairs and the results do not necessarily reflect the influence of tendon quality and healing on construct longevity. ${ }^{15}$ Third, the sample size used in this study may have underpowered some experimental measures. For example, there appeared to be trends in ultimate tensile strength that did not reach significance. Thus, a greater sample size may have offered greater statistical power with respect to ultimate tensile strength. Finally, while the two senior surgeons performing the procedures in this study were trained to carry out the repairs in an identical manner with the use of a suture-hole template and standardised Fiberwire lengths, there may have been some variations in the reconstructions, including those associated with suture tension, and this may have increased the dispersion of the data and influenced the statistical outcomes.

\section{CONCLUSION}

The present study demonstrated that the single-row cruciate suture repair exhibits less gap formation under loading than the Mason-Allen repair, and equivalent gap formation to the double-row equivalent SutureBridge repair. In addition, the cruciate suture repair construct was found to be of similar stiffness to the SutureBridge repair, and significantly stiffer than the Mason-Allen repair construct. Since the cruciate suture repair may ultimately be a faster, easier and more cost effective alternative to the double-row and double-row equivalent repairs, it may represent a more effective alternative to conventional single-row rotator cuff repairs. 


\section{REFERENCES}

1. Ackland DC, Roshan-Zamir S, Richardson M, Pandy MG. Muscle and joint-contact loading at the glenohumeral joint after reverse total shoulder arthroplasty. J Orthop Res. 2011;29(12):1850-1858.

2. Anderl W, Heuberer PR, Laky B, Kriegleder B, Reihsner R, Eberhardsteiner J. Superiority of bridging techniques with medial fixation on initial strength. Knee Surg Sports Traumatol Arthrosc. 2012;20(12):2559-2566.

3. Baleani M, Ohman C, Guandalini L, et al. Comparative study of different tendon grasping techniques for arthroscopic repair of the rotator cuff. Clin Biomech (Bristol, Avon). 2006;21(8):799-803.

4. Baums MH, Buchhorn GH, Spahn G, Poppendieck B, Schultz W, Klinger HM. Biomechanical characteristics of single-row repair in comparison to double-row repair with consideration of the suture configuration and suture material. Knee Surg Sports Traumatol Arthrosc 2008;16(11):1052-1060.

5. Bisson L, Zivaljevic N, Sanders S, Pula D. A cost analysis of single-row versus double-row and suture bridge rotator cuff repair methods. Knee Surg Sports Traumatol Arthrosc. 2015;23(2):487-493.

6. Caldow J, Richardson M, Balakrishnan S, Sobol T, Lee PV, Ackland DC. A cruciate suture technique for rotator cuff repair. Knee Surg Sports Traumatol Arthrosc. 2015;23(2):619-626.

7. Cummins C, Murrell G. Mode of failure for rotator cuff repair with suture anchors identified at revision surgery. J Shoulder Elbow Surg. 2003;12:2. 
8. Galatz LM, Ball CM, Teefey SA, Middleton WD, Yamaguchi K. The outcome and repair integrity of completely arthroscopically repaired large and massive rotator cuff tears. J Bone Joint Surg Am. 2004;86-A(2):219-224.

9. Gelberman RH, Boyer MI, Brodt MD, Winters SC, Silva MJ. The effect of gap formation at the repair site on the strength and excursion of intrasynovial flexor tendons. An experimental study on the early stages of tendon-healing in dogs. J Bone Joint Surg Am. 1999;81(7):975-982.

10. Gerber C, Schneeberger AG, Beck M, Schlegel U. Mechanical strength of repairs of the rotator cuff. $J$ Bone Joint Surg Br. 1994;76(3):371-380.

11. Harryman DT, 2nd, Mack LA, Wang KY, Jackins SE, Richardson ML, Matsen FA, 3rd. Repairs of the rotator cuff. Correlation of functional results with integrity of the cuff. J Bone Joint Surg Am. 1991;73(7):982-989.

12. Hettrich CM, Gasinu S, Beamer BS, et al. The effect of mechanical load on tendonto-bone healing in a rat model. Am J Sports Med. 2014;42(5):1233-1241.

13. Jost PW, Khair MM, Chen DX, Wright TM, Kelly AM, Rodeo SA. Suture number determines strength of rotator cuff repair. J Bone Joint Surg Am. 2012;94(14):e100.

14. Kim DH, Elattrache NS, Tibone JE, et al. Biomechanical comparison of a single-row versus double-row suture anchor technique for rotator cuff repair. Am J Sports Med. 2006;34(3):407-414.

15. Ma B, Wilson J, Puttlitz C. Biomechanical evaluation of arthroscopic rotator cuff repairs: Double-row compared with Single-row fixation. J Bone Joint Surg Am. 2006;88(2):403-410. 
16. Ma CB, Comerford L, Wilson J, Puttlitz CM. Biomechanical evaluation of arthroscopic rotator cuff repairs: double-row compared with single-row fixation. $J$ Bone Joint Surg Am. 2006;88(2):403-410.

17. Mazzocca AD, Millett PJ, Guanche CA, Santangelo SA, Arciero RA. Arthroscopic single-row versus double-row suture anchor rotator cuff repair. Am J Sports Med. $2005 ; 33(12): 1861-1868$.

18. McCarron JA, Derwin KA, Bey MJ, et al. Failure with continuity in rotator cuff repair "healing". Am J Sports Med. 2013;41(1):134-141.

19. Nelson CO, Sileo MJ, Grossman MG, Serra-Hsu F. Single-row modified mason-allen versus double-row arthroscopic rotator cuff repair: a biomechanical and surface area comparison. Arthroscopy. 2008;24(8):941-948.

20. Park MC, Tibone JE, ElAttrache NS, Ahmad CS, Jun BJ, Lee TQ. Part II: Biomechanical assessment for a footprint-restoring transosseous-equivalent rotator cuff repair technique compared with a double-row repair technique. J Shoulder Elbow Surg. 2007;16(4):469-476.

21. Sonnabend DH, Howlett CR, Young AA. Histological evaluation of repair of the rotator cuff in a primate model. J Bone Joint Surg Br. 2010;92(4):586-594.

22. Wellmann M, Wiebringhaus $\mathrm{P}$, Lodde I, et al. Biomechanical evaluation of a singlerow versus double-row repair for complete subscapularis tears. Knee Surg Sports Traumatol Arthrosc. 2009;17(12):1477-1484. 


\section{FIGURE LEGENDS}

Figure 1: Diagram illustrating the (A) cruciate suture, (B) Mason-Allen and (C) SutureBridge repair techniques.

Figure 2: The Instron Material Test system used for load application (A), tendon repair construct (B), and gap formation calculation (C). Humerus specimens were

$$
=
$$
embedded in cylindrical potting block using Plaster of Paris and the tendon repair constructs clamped using a customised sinusoidal grip clamps. A specimen ( alignment bracket was used to orient the specimen to ensure that the tendon was pulled in the direction of the muscle line of action. The upper cross-head was disp displaced upward at a constant rate while a load cell measured the force applied directly to the tendon. The locations of pairs of markers placed on the tendon and bone were measured using a high-speed camera and used to calculate gap formation. Gap formation at the $\mathrm{n}^{\text {th }}$ load cycle was calculated by subtracting the average distance between two tendon markers (blue dots) with respect to two humeral-fixed markers (black dots) at the first load cycle from the average distance between the two tendon markers at the $\mathrm{n}^{\text {th }}$ load cycle (red dots) with
respect to the two humeral-fixed markers. 


\section{TABLES}

Table 1: $\quad$ Gap formation (mm) at 50, 100, 150 and 200 load cycles, ultimate tensile strength $(\mathrm{N})$ and stiffness $(\mathrm{N} / \mathrm{mm})$ data for the cruciate suture, Mason-Allen and SutureBridge repair constructs. Mean and standard error of mean (SEM)

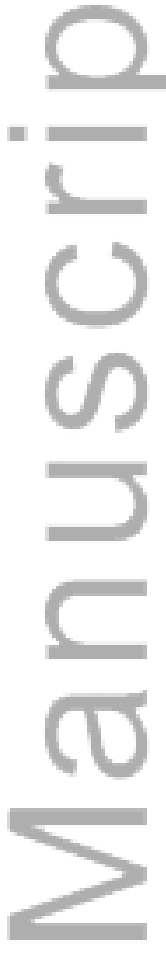
data are provided.

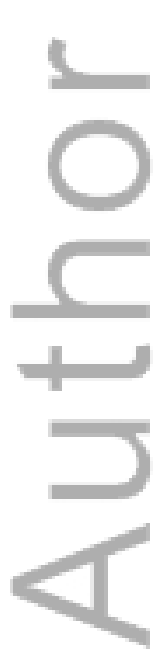

This article is protected by copyright. All rights reserved. 


\begin{tabular}{|c|c|c|c|c|c|c|c|c|c|c|c|c|}
\hline \multirow[b]{3}{*}{ Repair } & \multicolumn{7}{|c|}{ Gap Formation } & & & & \multirow{2}{*}{\multicolumn{2}{|c|}{$\begin{array}{l}\text { Ultimate } \\
\text { tensile } \\
\text { Strength }\end{array}$}} \\
\hline & \multicolumn{2}{|c|}{50 cycles } & \multicolumn{2}{|c|}{100 cycles } & \multicolumn{2}{|c|}{150 cycles } & \multicolumn{2}{|c|}{200 cycles } & \multicolumn{2}{|c|}{ Stiffness } & & \\
\hline & Mean & SEM & Mean & SEM & Mean & SEM & Mear & SEM & Mean & SEM & Mean & SEM \\
\hline Cruciate suture & 0.7 & 0.1 & 0.9 & 0.1 & 1.0 & 0.1 & 1.1 & 0.1 & 61.6 & 4.6 & 240.7 & 23.1 \\
\hline Mason-Allan & 1.2 & 0.2 & 1.4 & 0.2 & 1.6 & 0.2 & 1.7 & 0.2 & 45.8 & 4.4 & 184.1 & 15.7 \\
\hline SutureBridge & & 0.1 & 0.8 & 0.1 & 1.0 & 0.1 & 1.1 & 0.1 & 61.7 & 4.4 & 172.0 & 15.3 \\
\hline
\end{tabular}

$=$

Table 1: Gap formation ( $\mathrm{mm}$ ) at 50, 100, 150 and 200 load cycles, ultimate tensile strength $(\mathrm{N})$ and stiffness $(\mathrm{N} / \mathrm{mm})$ data for the cruciate suture, MasonAllen and SutureBridge repair constructs. Mean and standard error of mean (SEM) data are provided. 


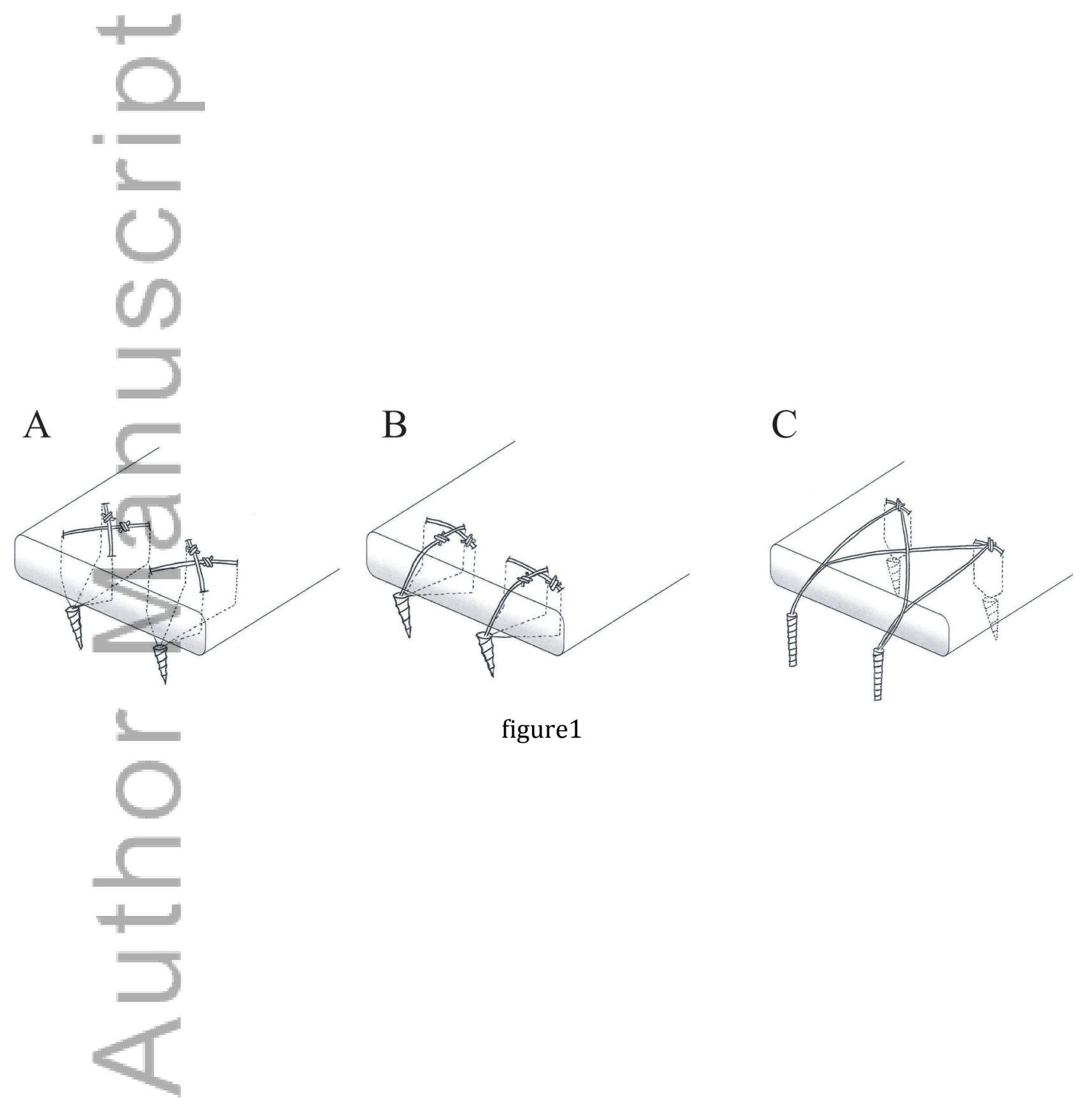

This article is protected by copyright. All rights reserved. 


\section{University Library}

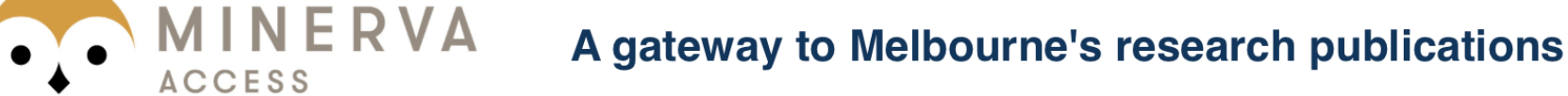

Minerva Access is the Institutional Repository of The University of Melbourne

Author/s:

Huntington, L;Richardson, M;Sobol, T;Caldow, J;Ackland, DC

Title:

Load response and gap formation in a single-row cruciate suture rotator cuff repair

Date:

2017-06-01

Citation:

Huntington, L., Richardson, M., Sobol, T., Caldow, J. \& Ackland, D. C. (2017). Load response and gap formation in a single-row cruciate suture rotator cuff repair. ANZ JOURNAL OF SURGERY, 87 (6), pp.483-487. https://doi.org/10.1111/ans.13875.

Persistent Link:

http://hdl.handle.net/11343/292363 